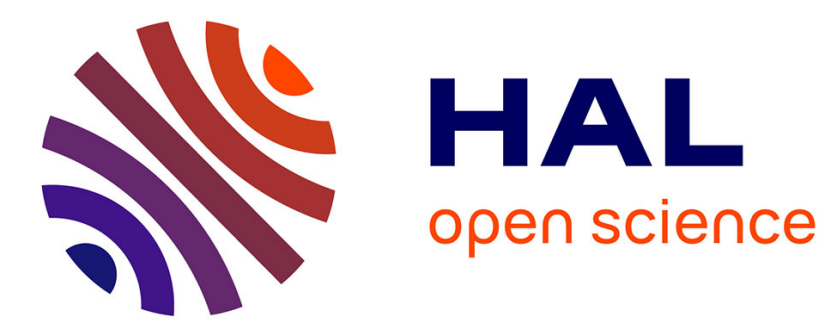

\title{
Transition metals as optically active dopants in glass-ceramics
}

L. Cormier, S. Zhou

\section{To cite this version:}

L. Cormier, S. Zhou. Transition metals as optically active dopants in glass-ceramics. Applied Physics Letters, 2020, 116 (26), pp.260503. 10.1063/5.0014618 . hal-02887012

\section{HAL Id: hal-02887012 \\ https://cnrs.hal.science/hal-02887012}

Submitted on 1 Jul 2020

HAL is a multi-disciplinary open access archive for the deposit and dissemination of scientific research documents, whether they are published or not. The documents may come from teaching and research institutions in France or abroad, or from public or private research centers.
L'archive ouverte pluridisciplinaire HAL, est destinée au dépôt et à la diffusion de documents scientifiques de niveau recherche, publiés ou non, émanant des établissements d'enseignement et de recherche français ou étrangers, des laboratoires publics ou privés. 


\title{
Transition metals as optically active dopants in glass-ceramics
}

\author{
L. Cormier ${ }^{1, a)}$ and S. Zhou ${ }^{2, b)}$ \\ 1) Sorbonne Université, CNRS UMR7590, MNHN, IRD, Institut de Minéralogie, de Physique des Matériaux et de \\ Cosmochimie (IMPMC), 4 place Jussieu, F-75005 Paris, France. \\ 2) State Key Laboratory of Luminescent Materials and Devices, Guangdong Provincial Key Laboratory of Fibre \\ Laser Materials and Applied Techniques, Guangdong Engineering Technology Research and Development \\ Center of Special Optical Fibre Materials and Devices, South China University of Technology, Guangzhou \\ 510640, China \\ a) laurent.cormier@sorbonne-universite.fr \\ b) zhoushifeng@scut.edu.cn
}

\section{Abstract}

Over the past decades, glass-ceramics doped with transition metals have become promising materials for the development of active and passive optical functional devices, interesting a wide variety of commercial applications due to their unique properties. In this Perspective paper, the intrinsic advantages of these composite materials are outlined and we provide an overview of recent and on-going progress and state-of-the-art knowledges of the main applications: broadband amplifiers, tunable lasers, long persistent phosphors, noninvasive optical temperature sensors, saturable absorbers, high IR emitters and thermal shock-resistant color filters. Finally, the today challenges and future prospects are exposed to provide guidelines for future research. 
Transition metal (TM) ions such as $\mathrm{Ni}^{2+}$ or $\mathrm{Cr}^{4+}$ are highly promising optically active ions in single-crystalline materials since they show rich electronic transitions in the near infra-red (NIR) region and they have wide applications to gain media for lasers. However, the manufacturing processes of single crystals seriously limit the flexibility in compositions, and the versatility to shape them in fibers or on large-scales. TM ions in glasses only exhibit poor luminescence behavior because the strong nonradiative decay processes dominate the relaxations of the excited state and coordination states are unfavorable. ${ }^{1,2,3}$ The gap between glasses and single crystals can be fulfilled by transparent glass-ceramics (TGCs) as these composite materials can offer optical properties similar to those of single crystals, provided that TM ions are incorporated into a suitable crystalline host. Owing to the enhancement of optical properties resulting from the incorporation of TM ions within nanosized crystals embedded into the glass matrix, TGCs have received significant and continuous attention and can offer promising alternatives to crystals in photoelectronic and photonic areas. This perspective letter focuses on recent advances in developing oxide TGCs doped with $3 \mathrm{~d}$ TM ions for active and passive optical applications. We discuss the recent improvements, existing challenges and future prospects of these nanocomposite materials, paving the way for new fabrication processes and new type of advanced functional materials.

TGCs relies on the in situ growth of nanocrystals (NCS) in a glass upon heating treatment (Figure 1). From the viewpoint of materials design, TMs can be purposely activated if the crystalline phases can provide suitable tetrahedral or octahedral sites. The resultant TGCs retain important advantages of crystals, such as high optical activity, combined with easy and flexible glass-forming manufacturing, making them cost efficient compared to single crystals and ceramics, with outstanding properties among which transparency, superior mechanical strength, tailorable thermal expansion coefficients used for high resistance to thermal shock. ${ }^{4,3}$ Additionally, their optical behavior can be almost completely designed by a high level of composition and processing control. Large scale samples or even fibers can be elaborated and sometimes functional crystals precipitated in TGCs are difficult or impossible to synthesize as single crystals, ${ }^{4,5}$ offering new functionalities.

TGCs are attractive as optical components as long as high transparency is achieved. The development of transparent glass-ceramics (TGCs) can be optimized in two ways: ${ }^{6}(1)$ by minimizing the refractive index difference $(<0.01)$ of the two phases (NCs and residual glass) 
or (2) by controlling the size of the NCs with a critical size much smaller (preferably $<30 \mathrm{~nm}$ ) than the wavelengths of the visible spectrum. The former allows the formation of large crystals up to micrometer scale while maintaining transparency. ${ }^{3}$ The second method controlling the size limit of NCs is more generally used though it requires a good mastering and understanding of the crystallization processes. The transparency usually requires volume (as opposed to surface) nucleation which is initiated by the addition of nucleation agents $\left(\mathrm{ZrO}_{2}\right.$ and/or $\mathrm{TiO}_{2}$ ) in moderate amounts. ${ }^{7}$ These agents promote phase separation that is enhanced by a heating treatment at $30-100^{\circ} \mathrm{C}$ above the annealing temperature of the glass. ${ }^{8}$

Fabrication of TGCs is a major advantage compared to single crystals, owing to the possibility to produce large pieces of arbitrary shapes and sizes adapted for commercialization. Optical GCs can be designed using various methods: traditional meltquenching followed by thermal heat treatments, sinter-crystallization ${ }^{10}$ or low-temperature techniques such as sol-gel ${ }^{11}$ or modified chemical vapor deposition. ${ }^{12}$ The reuse of industrial wastes as raw materials is also an important field that should develop in future years with both ecological and economical importance. ${ }^{13}$

The fabrication of the TGCs is tightly attached with the physical mechanism of nucleation and crystal growth in glass phase. It has been regarded as a challenging fundamental issue and the deep understanding is critical to manipulate the formation of NCs. Over the past years, the existence of mesoscale heterogeneities within glasses has been demonstrated as a determinant parameter in the underlying mechanism of nucleation. ${ }^{14,15,16,17}$ These mesoscale heterogeneities (Figure 2) may be further exploited for mastering the microstructure, the crystalline phase formation or the distribution of TMs. ${ }^{14}$ Benefiting from the substantial progress in revealing the structural nature of the parent glass for TGCs, in recent years, new methods of elaboration have emerged. In particular, laser-induced crystallization using TM $\left(\mathrm{Ni}^{2+}, \mathrm{Cu}^{2+}\right)$ atom heat processing opens new perspectives for localized or oriented crystallization, reshaping of NCs or for patterning, with high potential for new optical active devices. ${ }^{18,19}$ For practical and advanced applications, such as high-capacity telecommunication, biomedical remote sensing or compact light source, TGCs have to be ultimately produced in fiber geometry. The technique of melt-in-tube fiber drawing has stimulated many studies to obtain optical GC fibers. ${ }^{20,18,21,22}$ We can cite the realization of TGC fibers containing various crystals: $\mathrm{Cr}^{4+}-\mathrm{Mg}_{2} \mathrm{SiO}_{4},{ }^{21,23} \mathrm{Cr}^{3+}: \mathrm{ZnAl}_{2} \mathrm{O}_{4},{ }^{22} \mathrm{Ni}^{2+}-\mathrm{Li}(\mathrm{Ga}, \mathrm{Al})_{5} \mathrm{O}_{8}$ and 
$\mathrm{Ni}^{2+}: \gamma(\mathrm{Ga}, \mathrm{Al})_{2} \mathrm{O}_{3},{ }^{5,20}$ that should pave the way for commercially viable devices. Moreover, the material category has also been extended to more complicate systems such as novel multiphases ( $\mathrm{LiTaO}_{3}$ and $\mathrm{LiAlSi}_{2} \mathrm{O}_{6}$ ) TGC and even TGC fiber (Figure 2). ${ }^{14}$

Rare-earth (RE) ions show discrete energy levels due to purely $4 f-4 f$ electronic transitions (zero-phonon lines). These narrow bands yield limited applications for broad flatline-shape absorption and emission bands. On the contrary, the TM ions interact with the vibrations of the crystal lattice (vibronic coupling). ${ }^{24}$ The overlap between the excitation of an electronic transition and vibrational transitions gives intrinsic broad absorption bands, when TMs are located in specific environments in oxide matrices, e.g. $\mathrm{Cr}^{4+}$ and $\mathrm{Co}^{2+}$ in tetrahedral sites and $\mathrm{Ni}^{2+}$ in octahedral sites. As opposed to the $f$-level screening in the case of RE ions, the specificity of $3 d$ TM ions is that $d$ - $d$ transitions are strongly dependent on their local ligand field because the $d$-orbitals are only weakly shielded from the surrounding neighbors.

Another prominent feature is that controllable energy transfer can be realized in TM ions doped TGCs. The energy transfer process can be simply described by using two interacting dopants with the energy donor as sensitizer and energy receiver as activator. In this process, an excited state energy is transferred, in whole or partly, from a sensitizer to an activator by nonradiative and radiative processes. ${ }^{25} \mathrm{~A}$ high energy transfer is expected when the emission spectrum of the sensitizer widely overlaps the absorption spectrum of the activator and when the sensitizer-activator distance is short (energy transfer rate proportional to $r^{-6}$, with $r$ the separation distance). ${ }^{14,18}$ The strength of interaction is strong for allowed transitions (broad bands) as opposite to forbidden transitions (narrow lines). Recent progresses have been demonstrated to develop diverse combinations of codoped ions based on this method of energy transfer due to impurity-sensitizers.

On one hand, the energy transfer process can be utilized for improving the luminescence brightness in TMs doped TGCs. Octahedral $\mathrm{Cr}^{3+}$ sites have a broad and strong absorption in the visible region and fluoresce in the red and NIR region. Under $532 \mathrm{~nm}$ excitation, $\mathrm{Cr}^{3+}$ is a desirable sensitizer because its NIR emission overlaps well with the NIR absorption of $\mathrm{Ni}^{2+}$, resulting to an efficient energy transfer from $\mathrm{Cr}^{3+}$ to $\mathrm{Ni}^{2+}$ ions. In consequence, $\mathrm{Cr}^{3+} / \mathrm{Ni}^{2+}$ codoping has been investigated in several TGCs: $\mathrm{Cr}^{3+} / \mathrm{Ni}^{2+}$ codoped spinels $\mathrm{NCs}$ in $\mathrm{ZnO}-\mathrm{Al}_{2} \mathrm{O}_{3}-\mathrm{SiO}_{2}$ GCs and $\mathrm{MgO}-\mathrm{Al}_{2} \mathrm{O}_{3}-\mathrm{SiO}_{2} \mathrm{GCs}^{25,26}$ and $\mathrm{Cr}^{3+} / \mathrm{Ni}^{2+}$ codoped $\mathrm{LiGa}_{5} \mathrm{O}_{8}$ in $\mathrm{Li}_{2} \mathrm{O}-\mathrm{Ga}_{2} \mathrm{O}_{3}-\mathrm{SiO}_{2}$ GCs. ${ }^{27}$ Compared to $\mathrm{Ni}^{2+}$ single-doped materials, co-doping enhances emission intensity by 
approximately 8 times. The energy transfer is confirmed by time-resolved emission spectra with an efficiency that can reach $85 \%$. Similarly, enhancement of NIR luminescence is observed in $\mathrm{Yb}^{3+} / \mathrm{Ni}^{2+}$-codoped transparent $\mathrm{GCs}$ as $\mathrm{Ni}^{2+}$ ions are activated by $\mathrm{Yb}^{3+}$ sensitizing. ${ }^{28,29} \mathrm{Cr}^{3+}$ ions are also competitive energy sensitizers in RE-based laser solids because the visible and NIR emissions of $\mathrm{Cr}^{3+}$ significantly overlap with the absorption of RE $\left(\mathrm{Nd}^{3+}, \mathrm{Tm}^{3+}\right)$ ions. ${ }^{26,30} \mathrm{~Tb}^{3+}$ was also used as an efficient sensitizer for ${ }^{[6]} \mathrm{Mn}^{2+}$ in $\mathrm{ZnAl}_{2} \mathrm{O}_{4} \mathrm{NCs}$ embedded in a GC, giving intense red photoemission. ${ }^{31}$ The energy transfer process upon 350 $\mathrm{nm}$ excitation can be controlled by the crystallization conditions and the dopant concentrations allowing the color of photoemission to be tuned by simultaneous emission of $\mathrm{Tb}^{3+}$ and $\mathrm{Mn}^{2+}$ centers. A potential application of this material is considered as single or dualmode emitting phosphor for luminescent lighting.

On the other hand, the rational control of the energy transfer process, with even suppressing the process if unwanted, is also an interesting topic in TMs doped TGCs. ${ }^{32}$ The partition of the different dopants into the crystalline phases is a major challenge to efficiently manage energy transfers. ${ }^{32,33,34}$ It was demonstrated that an efficient energy transfer results from accumulation of $\mathrm{RE}\left(\mathrm{Er}^{3+}, \mathrm{Yb}^{3+}\right)$ ions inside $\left(\mathrm{Ni}^{2+}, \mathrm{Cr}^{3+}\right): \gamma-\mathrm{Ga}_{2} \mathrm{O}_{3} \mathrm{NCs}$, enabling different energy transfers $\mathrm{Yb}^{3+} \rightarrow \mathrm{Ni}^{2+}, \mathrm{Ni}^{2+} \rightarrow \mathrm{Er}^{3+}$ and $\mathrm{Er}^{3+} \rightarrow \mathrm{Cr}^{3+}$. 35 A strategy was recently proposed to control the energy transfer between $\mathrm{Er}^{3+}$ and $\mathrm{Ni}^{2+}$ in dual-phases $\mathrm{GCs}$ by a selective incorporation of these active centers in $\mathrm{LaF}_{3}$ and $\mathrm{Ga}_{2} \mathrm{O}_{3} \mathrm{NCs} .{ }^{32} \mathrm{~A}$ treatment at low temperature allows energy transfer between $\mathrm{Er}^{3+}$ and $\mathrm{Ni}^{2+}$ in $\mathrm{Ga}_{2} \mathrm{O}_{3}$ while a treatment at high temperature confines the two ions either in $\mathrm{LaF}_{3}\left(\mathrm{Er}^{3+}\right)$ or $\mathrm{Ga}_{2} \mathrm{O}_{3}\left(\mathrm{Ni}^{2+}\right)$ and suppresses energy transfer. The latter partitioning can be reproduced with ultra-short laser pulse-induced crystallization giving a composite material with multicolor emissions. The thermometric performances for temperature sensing should also be boosted by temperature-dependent energy transfer based on co-doping between TM, RE and $\mathrm{Ln}^{3+}$ ions $(\mathrm{Ln}=\mathrm{Er}, \mathrm{Ho}) .{ }^{36}$ Finally, the energy transfer from $\mathrm{Cr}^{3+}$ to $\mathrm{Yb}^{3+}$ in a YAG GC can be advantageously used to converts the VIS sunlight to NIR emission at $1030 \mathrm{~nm}$ with a high efficiency. ${ }^{37}$

The development of luminescent materials in the near infra-red window has been extensively explored, achieving some promising results in the field of telecommunication and information technology (broadband amplifiers, tunable lasers, smart solid-state lighting) ${ }^{38,39}$, in medical diagnostic and surgery (bioimaging, photodynamic therapy) ${ }^{40,41}$ and, in general, in 
the area of photoelectronics and photonics. ${ }^{14,3}$ Luminescence phenomenon originates from a wide optical gap present in the electronic band structure or from luminescent centers giving localized electronic states within the gap. ${ }^{42,24}$ The most common centers are TM or RE ions. TGCs doped with TM ions are potential effective candidates due to enhancement of the photoluminescence efficiency and very broad bands, depending on the ion environment and concentration and the excitation. These materials show broadband NIR emissions: for instance, $\mathrm{Cr}^{3+}$ ion, ${ }^{43} \mathrm{Cr}^{4+}$ and $\mathrm{Ni}^{2+}$ ions ${ }^{44,45,46}$ have wide emissions covering the $1200-1600 \mathrm{~nm}$ range, which is the region of interest to extend the optical communication transmission window. Indeed, the design of new fiber amplifiers or laser sources with a wide and flat gain bandwidth is a promising perspective to achieve more efficient wavelength division multiplexing transmission network giving higher capacity and faster bit rate to revolutionize future optical communications. ${ }^{38,39}$ Furthermore, novel light sources emitting in the NIR are highly desirable because this is the region of transparency of biological tissues (little autofluorescence and low transmission loss of optical signal). ${ }^{47,41}$

$\mathrm{Ni}^{2+}$ ions are considered as the most promising choice of optical active center, when localized in octahedral coordination $\left({ }^{[6]} \mathrm{Ni}^{2+}\right)$, as they exhibit a broadband NIR emission with a high quantum yield and a long fluorescence lifetime and nickel has a stable valence state. Promising ${ }^{[6]} \mathrm{Ni}^{2+}$-doped crystals have been selected and precipitated in several TGC systems: $ß-\mathrm{Ga}_{2} \mathrm{O}_{3},{ }^{48,49,32,50}$ different types of spinels, ${ }^{46,51,52,11,53,54}$ hollandite-type $\mathrm{BaAl}_{2} \mathrm{Ti}_{6} \mathrm{O}_{16},{ }^{55}$ mullite $\left(\mathrm{Ga}_{2} \mathrm{O}_{3}\right)_{3}\left(\mathrm{GeO}_{2}\right)_{2},{ }^{47}$ hexacelsian $\mathrm{Ba}_{0.808}\left(\mathrm{Al}_{1.71} \mathrm{Si}_{2.29}\right) \mathrm{O}_{8}{ }^{47}$ and perovskite $\mathrm{SrTiO}_{3} .^{56}$ In particular, spinel-like compounds have attracted considerable attention as an appropriate crystalline host to insert ${ }^{[6]} \mathrm{Ni}^{2+}: \mathrm{AB}_{2} \mathrm{O}_{4}$ spinels, in which $\mathrm{A}$ can be $\mathrm{Mg},{ }^{51,52}$ or $\mathrm{Zn},{ }^{11}$ or a mixture of $\mathrm{Mg}$ and $\mathrm{Zn},{ }^{53}$ and $\mathrm{B}$ can be $\mathrm{Al}$ or $\mathrm{Ga}$, or spinel $\mathrm{LiGa}_{5} \mathrm{O}_{8}{ }^{46}$ The $\mathrm{Ga}_{2} \mathrm{O}_{3}$ addition in spinel NCs largely enhances the luminescent intensity of $\mathrm{Ni}^{2+}, 57,58$ which could be ascribed to the strong preference of $\mathrm{Ga}^{3+}$ ions for tetrahedral site, ${ }^{50}$ and the decrease of the mean frequency of phonon density of states in the spinel solid solutions. ${ }^{57}$ The parent glass compositions suitable for crystallization of desired crystals are often synthesized with addition of titania and/or zirconia as nucleating agents. ${ }^{7,59,60,61,62,63,64}$ The incorporation of $\mathrm{TiO}_{2}$, initially to promote volume nucleation, can also play a favorable role by drastically increasing both the luminescence intensity and lifetime. The reason of the enhancement is identified as the substitution of $\mathrm{Ga}^{3+}$ by $\mathrm{Ni}^{2+}+\mathrm{Ti}^{4+}$ with $\mathrm{Ti}^{4+}$ being a charge compensator. ${ }^{58}$ 
Compared to state-of-the-art erbium-based optical amplifiers, ${ }^{50}$ effective emission bandwidths are usually large and can reach $400 \mathrm{~nm}$ for $\mathrm{Ni}^{2+}: \mathrm{Mg}_{x} \mathrm{Zn}_{1-x} 1 \mathrm{Ga}_{2} \mathrm{O}_{4} \mathrm{TGC}^{65}$ Internal fluorescence quantum efficiency $(\eta)$ is slightly increased in TGCs compared to crystals (for instance, $\sim 25 \%$ for $\mathrm{Ni}^{2+}: \mathrm{ZnGa}_{2} \mathrm{O}_{4}$ TGCs compared to $\sim 18 \%$ for a pure $\mathrm{Ni}^{2+}$-doped $\mathrm{ZnGa}_{2} \mathrm{O}_{4}$ crystal). ${ }^{66}$ High quantum efficiency are observed in TGCs containing $\mathrm{Ni}^{2+}: \mathrm{ZnAl}_{2} \mathrm{O}_{4}(\sim 55 \%),{ }^{44}$ $\mathrm{Ni}^{2+}: \mathrm{LiGa}_{5} \mathrm{O}_{8}(\sim 60 \%)^{46}$ and $\mathrm{Ni}^{2+}: \mathrm{BaAl}_{2} \mathrm{Ti}_{6} \mathrm{O}_{16}$ ( 65\%). ${ }^{55,67}$ Optical amplification can be limited due to low emission efficiency and high scattering loss, ${ }^{3}$ but a gain coefficient of $0.283 \mathrm{~cm}^{-1}$ at 1300 $\mathrm{nm}$ (pumping: $980 \mathrm{~nm}, 1.12 \mathrm{~W}$ ) was demonstrated in a $\mathrm{Ni}^{2+}: \mathrm{B}_{-} \mathrm{Ga}_{2} \mathrm{O}_{3}$ flat plate $\mathrm{TGC} .{ }^{49}$ For potential applications, TGCs must also be easily drawn into fibers with embedded ${ }^{[6]} \mathrm{Ni}^{2+}$ doped crystals. Fortunately, the corresponding fibers have been successfully fabricated and they are highly attractive for high-capacity optical communication devices. ${ }^{3,14,20}$

An interesting advantage of TGC is the ability to manipulate the composite to tune the optical properties, ${ }^{32}$ such as the position and shape of the NIR emission band and the decay kinetics. This can be achieved by precise tailoring of the TGC composition to modify the local ligand field symmetry and strength, ${ }^{14,47}$ by controlling the nature and content of nucleating

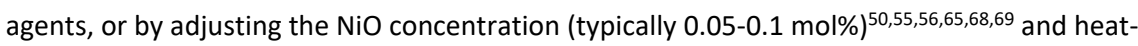
treatment conditions to control the nature, quantity and size of NCs. ${ }^{54,55,69,70}$ In the specific case of $\mathrm{Ni}^{2+}: \mathrm{SrTiO}_{3} \mathrm{GC}$, the fluorescent lifetime increases with the $\mathrm{NiO}$ concentration up to $0.1 \mathrm{wt} \%$. Above this latter value, the performances rapidly decrease due to the fluorescence quenching resulting from the energy transfer between close $\mathrm{Ni}^{2+}$ ions. ${ }^{56}$ Interestingly, the $\mathrm{Ni}$ doping level influences the domain size of a Ga-oxide phase, suggesting that Ni plays a relevant role in crystal nucleation and growth of the segregated nanophase..$^{50,55}$

Unlike trivalent RE ions, the $d$ - $d$ transition of $\mathrm{Ni}^{2+}$ strongly depends on the interaction of the $3 \mathrm{~d}$-electrons with the nearest neighbors and the local symmetry around $\mathrm{Ni}^{2+}$ ions, which is measured by the crystal field strength $D q$ determined from the absorption spectra. ${ }^{49,3} \mathrm{~A}$ long fluorescent lifetime and a broadband optical amplification have been observed only for a high crystal field strength. ${ }^{18}$ The effect of ligands on the absorption and emission spectra has been exploited in a TGC containing $\mathrm{Ni}^{2+}: \mathrm{B}_{-}-\mathrm{Ga}_{2} \mathrm{O}_{3} \mathrm{NCs}$, by partial substitution of $\mathrm{Ga}^{3+}$ and $\mathrm{O}^{2-}$ with $\mathrm{In}^{3+}$ or $\mathrm{F}^{-}{ }^{-11}$ By simply manipulating the optically inactive codopants, the emission can be rationally triggered from 1200 to $1400 \mathrm{~nm}$, corresponding to the whole telecommunication window, and the decay rate can also be managed. The lifetimes of the longest component 
were estimated to be around $1537 \mu \mathrm{s}\left(\mathrm{Ni}^{2+}\right), 1351 \mu \mathrm{s}\left(\mathrm{Ni}^{2+} / \mathrm{In}^{3+}\right), 639 \mu \mathrm{s}\left(\mathrm{Ni}^{2+} / \mathrm{F}^{-}\right)$and $332 \mu \mathrm{s}$ $\left(\mathrm{Ni}^{2+} / \mathrm{F}^{-} / \mathrm{In}^{3+}\right)$, which correspond to the order of $D q$. Interestingly, a spectral broadening is noticeable exclusively in $\mathrm{F}^{-}$-doped samples, which is ascribed to the strong local ligand distortion after $\mathrm{F}^{-}$addition. The IR luminescent band can be also purposely broadened by judiciously localized $\mathrm{Ni}^{2+}$-doped TGCs in multiple octahedral local environments, either in a single crystalline phase with different octahedral sites or in a combination of different crystalline phases offering different octahedral positions. ${ }^{47,18}$ A significant inhomogeneous emission broadening was achieved with a bandwidth up to $\sim 480 \mathrm{~nm}$ for TGC, associated with an extremely flat spectral shape covering the whole telecommunication low loss window (1260-1675 nm). This opens up new avenues for better engineering the spectral broadening. ${ }^{14}$

$\mathrm{Cr}^{4+}$ is another TM activator, having a broadband NIR emission in the optical communication window when it occupies a tetrahedral position. ${ }^{3{ }^{[4]}} \mathrm{Cr}^{4+}$ ions can be found in substitution of $\mathrm{Si}$ or $\mathrm{Ge}$ in various crystals precipitated in TGCs like $\mathrm{Ca}_{2} \mathrm{Al}_{2} \mathrm{SiO}_{7}, \mathrm{Mg}_{2} \mathrm{SiO}_{4}$, $\mathrm{Li}_{x} \mathrm{Zn}_{y} \mathrm{SiO}_{4}$ and $\mathrm{Ca}_{2} \mathrm{GeO}_{4} \cdot{ }^{9,43,45,72,73,74,75}$ The different ligand fields enable to tailor the NIR luminescence from 1130 to $1350 \mathrm{~nm}$ and the lifetime from 6 to $100 \mu \mathrm{s} .{ }^{9}$ However, the parasitic presence of $\mathrm{Cr}^{3+}$ and $\mathrm{Cr}^{6+}$ is difficult to avoid and, in practice, these ions will quench the NIR luminescence from $\mathrm{Cr}^{4+}$ and limit the observation of optical amplification. Nevertheless, an optical gain of $1.27 \mathrm{~cm}^{-1}$ (pumping: $808 \mathrm{~nm}, 0.8 \mathrm{~W}$ ) was realized in a $\mathrm{Cr}^{4+}: \mathrm{Li}_{2} \mathrm{ZnSiO}_{4} \mathrm{TGC}$, achieving a quantum yield of $17 \% .{ }^{9,72}$ Some $\mathrm{Cr}^{4+}$-doped TGCs were considered as an appropriate alternative for an active laser media (for instance $\mathrm{Cr}^{4+}-\mathrm{LiGaSiO}_{4} \mathrm{TGCs}$ ) ${ }^{76}$ but no laser action has been demonstrated.

Other fields could benefit of the introduction of TM ions in GCs. Octahedrally coordinated $\mathrm{Cr}^{3+}$ ions have been successfully prepared in TGCS as lamp-pump laser active centers and as luminescent solar concentrators by doping various crystalline phases: ${ }^{26}$ spinels, mullite, ß-quartz solid solution, and $\mathrm{ZrO}_{2}{ }^{62}$ Finally, a red emission of ${ }^{[6]} \mathrm{Mn}^{4+}: \mathrm{Li}_{2} \mathrm{Ge}_{4} \mathrm{O}_{9}$ crystals has been obtained in a $20 \mathrm{Li}_{2} \mathrm{O}-80 \mathrm{GeO}_{2}-\mathrm{XMnO}_{2} \mathrm{GCs} .{ }^{77} \mathrm{~A}$ red-blue color can be tuned with $\mathrm{Mn}^{4+}$ concentration and remarkable quantum yield of $40 \%$ has been observed. However, the photoluminescence rapidly drops with temperature around $100^{\circ} \mathrm{C}$.

The design of novel long persistent phosphors (LPPs) stimulates intense research with widespread applications and commercializations, as dark/night environment vision materials for security route signage, identification markers, displays or medical diagnostics. ${ }^{78,79,80}$ 
Several TGCs have been designed with $\mathrm{Cr}^{3+}$ and $\mathrm{Mn}^{2+}$ ions precipitated in spinel $\mathrm{Zn}_{1+\mathrm{x}} \mathrm{Ga}_{2-}$ ${ }_{2 x} \mathrm{Ge}_{x} \mathrm{O}_{4}(0 \leq x \leq 1)$ or $\mathrm{LiGa}_{5} \mathrm{O}_{8}$ to realize materials that can emit for multiple hours after the excitation stoppage. ${ }^{46,81,82,83,84} \mathrm{Mn}^{2+}$ ions show remarkable emissions from red to orange and green with decreasing crystal fields. ${ }^{85}$ This property has been successfully exploited in $\mathrm{Mn}^{2+}: \mathrm{Zn}_{1+x} \mathrm{Ga}_{2-2 x} \mathrm{Ge}_{x} \mathrm{O}_{4} \mathrm{NCs}$ to obtain controllable, multi-color persistent luminescence, giving the possibility to change the crystal field around $\mathrm{Mn}^{2+}$ with different devitrification processes upon annealing. ${ }^{81} \mathrm{GCs}$ containing ${ }^{[6]} \mathrm{Cr}^{3+}: \mathrm{Zn}_{1+x} \mathrm{Ga}_{2-2 x} \mathrm{Ge}_{\mathrm{x}} \mathrm{O}_{4} \mathrm{NCs}$ have been considered for red phosphors design as they exhibit persistent red-luminescence afterglow and temperature sensing properties. ${ }^{46,83}$ The substitution of $\mathrm{Ga}^{3+}$ by $\mathrm{Ge}^{4+}$ and $\mathrm{Zn}^{2+}$ yields brighter and longer persistence luminescence due to a spinel inversion: $\mathrm{Ga}^{3+}$ ions replace $\mathrm{Zn}^{2+}$ in tetrahedral sites forming anti-site defects $\left(\mathrm{Ga}^{\bullet} \mathrm{zn}\right)$ that are responsible for distortion of ${ }^{[6]} \mathrm{Cr}^{3+}$ neighborhood and for enhancement of $\mathrm{Cr}^{3+}$ emission. ${ }^{82}$ The red long-lasting luminescence properties is further improved (great enhancement of the brightness and decay time) by introducing Ge and Sn to the spinel structure. The substitution creates distorted ${ }^{[6]} \mathrm{Cr}^{3+}$ sites surrounded by octahedral Ge and Sn positive substitutional defects that likely act as new efficient traps. ${ }^{82}$ Nanocrystalline high-albite $\mathrm{Mn}^{2+}: \mathrm{Na}(\mathrm{Al}, \mathrm{Ga}) \mathrm{Ge}_{3} \mathrm{O}_{8}$ have been precipitated in sodium gallium aluminum germanate glasses. ${ }^{41}$ Even with small NC sizes $(<50 \mathrm{~nm})$, red to NIR persistent luminescence cover the $600-800 \mathrm{~nm}$ region corresponding to that of transparency for biological tissues (650 - $1300 \mathrm{~nm}$ ) with an afterglow duration lasting more than 100 hours. These materials are envisaged for applications to in vivo bioimaging or photodynamic tumor therapy. The persistent luminescent TGC embedded with $\mathrm{Mn}^{2+}: \mathrm{ZnGa}_{2} \mathrm{O}_{4}$ shows an interesting pressure sensitive green luminescence. Based on this unique feature, the new concept of smart active glass has been proposed and TM ions have been demonstrated to be promising candidates for the related applications. ${ }^{86}$

Materials having high temperature dependency of their luminescence lifetime have attracted much attention as candidate optical temperature sensors in electro-magnetically and/or thermally harsh environments. ${ }^{87}$ TGCs are attractive as they can offer continuous realtime reading, high spatial resolution and high temperature sensitivity. Recently, a TGC with a chromium partitioning of a majority $\mathrm{Cr}^{4+}$ in a $\mathrm{ZnO}-\mathrm{SrO}_{-} \mathrm{SiO}_{2}$ glass and a minority $\mathrm{Cr}^{3+}$ in a $\mathrm{ZnAl}_{2} \mathrm{O}_{4}$ crystalline sub-phase was obtained. A high temperature sensitivity $\left(1.72 \% \mathrm{~K}^{-1}\right)$ was achieved for $\mathrm{Cr}^{4+}$ compared to $\mathrm{Cr}^{3+}\left(0.83 \% \mathrm{~K}^{-1}\right)$, which is also significantly higher than typical 
$\mathrm{Cr}^{3+}$-based optical thermometric sensing materials. ${ }^{87,88}$ Multi-modal temperature sensing is a promising route to generate a large temperature range with high sensitivity. This approach is currently exploited by the selective incorporation of RE, $\mathrm{Ln}^{3+}$ or TM ions into different NCs. ${ }^{89}$ For instance, $\mathrm{Ln}^{3+}$ and $\mathrm{Cr}^{3+}$ ions incorporated into $\mathrm{GdF}_{3}$ and $\mathrm{Ga}_{2} \mathrm{O}_{3}$ nanophases via controlled glass crystallization of TGCs leads to a much improve temperature sensitivity (up to $15-22 \% \mathrm{~K}^{-}$ 1). 90

Passive Q-switching (PQS) is an optical component inserted into the laser cavity to generate short laser pulse duration from nano- to subnano-seconds, allowing fabrication of compact solid-state mini-lasers and microchip lasers. ${ }^{8,91}$ It consists of a saturable absorber (SA) for which the absorption decreases with increasing fluence of the incident radiation (photobleaching effect). ${ }^{91}$ Eye-safe Er lasers have emission wavelengths in the region 1500$1700 \mathrm{~nm}$, thus requiring a SA having an absorption band that matches the range from visible to Middle-IR (MIR) wavelengths. Additionally, low saturation fluence, fast recovery time of the initial absorption, low non-saturable losses and high laser damage threshold are required. ${ }^{4}$ TGCs containing tetrahedrally coordinated TM ions $\left(\mathrm{Co}^{2+}, \mathrm{V}^{3+}, \mathrm{Cr}^{4+}\right.$, etc.) have been widely considered as SAs for NIR lasers, ${ }^{3,8,91}$ as they exhibit strong nonlinear absorption of their broad absorption bands in the NIR-MIR region. This is the case of ${ }^{[4]} \mathrm{Co}^{2+}$ for which the broadband absorption overlaps the $1540 \mathrm{~nm}$ emission of $\mathrm{Er}^{3+}$-doped in crystal and glass lasers. TGCs based on different nanosized spinels doped with $\mathrm{Co}^{2+}$ were developed in aluminosilicate systems with interesting performances. ${ }^{92,93,94,95}$ For instance, a saturable absorption has been reported for TGCs containing both $\mathrm{Co}^{2+}: \mathrm{B}_{-} \mathrm{Zn}_{2} \mathrm{SiO}_{4}$ and $\mathrm{Co}^{2+}: \mathrm{ZnO} \mathrm{NCs}{ }^{91}$ The absorption characteristics (low saturation fluence of $0.75 \mathrm{~J} . \mathrm{cm}^{-2}$ at $1540 \mathrm{~nm}$, short recovery time of 830 $\mathrm{ns}$, and high laser damage threshold of $14 \mathrm{~J} . \mathrm{cm}^{-2}$ ) enable this TGC to be a SA solution for diodepumped $\mathrm{Er}, \mathrm{Yb}$ :glass lasers, resulting in the generation of Q-switched pulse of $0.77 \mathrm{~mJ}$ energy with a pulse duration of 45 ns. Similar properties were also demonstrated for a TGC containing $\mathrm{Co}^{2+}: \gamma-\mathrm{Ga}_{2} \mathrm{O}_{3} \mathrm{NCS}$, with the shortest $(1300 \mathrm{~nm})$ and longest wavelength edge $(1780 \mathrm{~nm})$ among the known cobalt-doped TGC materials. ${ }^{96,97}$ However, ultrafast pulse compression into ps or fs range are not possible with TM ions as their $3 d$ level lifetime are typically of the order of micro- to nanoseconds. Quantum-dot glasses are best candidates for such fast response times. ${ }^{3}$ The idea of optical modulation component has been successfully extended to other types of TM ions or TGCs. TGCs containing $\mathrm{Cr}^{4+}: \mathrm{Mg}_{2} \mathrm{SiO}_{4} \mathrm{NCs}$ were successfully fabricated based on a local chemistry engineering strategy. This candidate helps to achieve pulse laser 
with the shortest wavelength edge $(1060 \mathrm{~nm}, 176 \mathrm{~ns})$ among TM-doped TGC materials. Importantly, a wide frequency range from 800 to $1200 \mathrm{~nm}$ can also be expected based on the unique broadband feature of the constructed TGCs. ${ }^{98}$ In addition, co-doping of $\mathrm{Co}^{2+}$ with $\mathrm{Er}^{3+}$ would be attractive because a gain medium and a SA could be combined, which would appreciably simplify the laser cavity design. A good candidate could be a TGC that selectively incorporates $\mathrm{Co}^{2+}$ and $\mathrm{Er}^{3+}$ ions in different phases, $\mathrm{ZnAl}_{2} \mathrm{O}_{4}$ and $\mathrm{YF}_{3}$, respectively. ${ }^{99}$ The isolation of the two ions is useful to suppress energy transfer between the ions while maintaining the efficient SA characteristics of $\mathrm{Co}^{2+}: \mathrm{ZnAl}_{2} \mathrm{O}_{4}$ and the excellent luminescent performance of $\mathrm{Er}^{3+}: \mathrm{YF}_{3}$.

The effect of the TM ions doping on the IR emissivity of GCs has been particularly considered for energy saving solutions in architecture. ${ }^{3}$ Titanium slags and fly ashes were used as raw materials to obtain a GC containing a cordierite solid solution incorporating iron ions. ${ }^{13}$ The presence of $\mathrm{Fe}^{2+} / \mathrm{Fe}^{3+}$ impurities acting as lattice defects improved properties with a high IR irradiance and a low thermal expansion coefficient. Further it was demonstrated that a GC synthesized by using pure oxides as the starting materials improve further the material performances by increasing the waveband IR emissivity. ${ }^{100,101}$

Lastly, TM-doped GCs can also have significant contributions as thermal shock-resistant color filters for laser systems and high-power light sources. ${ }^{92,4}$ TGCs with a low coefficient of thermal expansion have been developed in the $\mathrm{Li}_{2} \mathrm{O}-\mathrm{Al}_{2} \mathrm{O}_{3}-\mathrm{SiO}_{2}$ system. By varying the heattreatment temperature, the TM optically active ions can be favored in different NCs, producing various tints (violet, blue, green, red, purple, and neutral). For instance $\mathrm{Ni}^{2+}$ ions in spinel NCs give a green color while, in $\beta$-quartz solid solution, these ions give purple and red tints. ${ }^{102}$

Though great successes have been made, challenges and prospects may be addressed in the future for the development of TM activated TGCs:

(i) Theoretically, various types of crystalline phases can be potentially precipitated inside TGCs. Currently, the matrixes suitable for hosting TM dopants are still highly limited. Therefore, exploration of new categories of TM-doped TGCs is considered as one of the main tasks in future research.

(ii) The co-doping of TMs and REs ions has promising applications and offer a rich variety of tunable properties for active, passive and up conversion devices, often based on 
energy transfer processes. This combination of active ions still requires important efforts to be developed and explored.

(iii) As compared with single crystals, the main disadvantage of TGCs is that active ions are not only concentrated within the desired phase, but they can remain in the parent glass or at the glass-crystal interfaces, resulting to optical losses of the material..$^{92}$ Thus, new strategies to confine TM dopants into crystalline phases in TGCs are expected to be highly beneficial for upgrading their optical performance.

(iv) As a typical composite, the volume ratio of crystalline phase and glass matrix dominates the optical performance of TM activated TGCs. On one hand, the content of crystalline phases should be increased as high as possible to enhance the optical activity of TGCs. On the other hand, the increase of the crystalline volume fraction in glass matrix may cause undesired optical scattering, which may deteriorate the optical quality of TGCs. Thus, finding the optimal balance relies strictly on a deep insight into the fundamental light-matter interactions in TM activated TGCs and a high level of understanding and control of the processing conditions.

All these future directions should stimulate intense fundamental research to discover new systems, have a rational design of these composite materials and develop new functionalities that could improve current performances or initiate novel applications.

\section{AUTHOR'S CONTRIBUTIONS}

All authors contributed equally to this work.

DATA AVAILABILITY

Data sharing not applicable - no new data generated

\section{REFERENCES}


${ }^{1}$ B. Wu, N. Jiang, S. Zhou, D. Chen, C. Zhu, and J. Qiu, Opt. Mater. 30, 1900 (2008).

${ }^{2}$ D. Deng, H. Ma, S. Xu, Q. Wang, L. Huang, S. Zhao, H. Wang, and C. Li, J. Non-Cryst. Solids 357, 1426 (2011).

${ }^{3}$ X. Liu, J. Zhou, S. Zhou, Y. Yue, and J. Qiu, Progress in Materials Science 97, 38 (2018).

${ }^{4}$ O. Dymshits, M. Shepilov, and A. Zhilin, MRS Bull. 42, 200 (2017).

${ }^{5}$ B.N. Samson, L.R. Pinckney, J. Wang, G.H. Beall, and N.F. Borrelli, Opt. Lett. 27, 1309 (2002).

${ }^{6}$ P.A. Tick, N.F. Borrelli, and I.M. Reaney, Opt. Mater. 15, 81 (2000).

${ }^{7}$ A. Dugué, O. Dymshits, L. Cormier, B. Cochain, G. Lelong, A. Zhilin, and S. Belin, J. Phys. Chem. Solids 78, 137 (2015).

${ }^{8}$ A.M. Malyarevich and K.V. Yumashev, J Appl Spectrosc 76, 1 (2009).

${ }^{9}$ Y. Zhuang, S. Tanabe, and J. Qiu, J. Am. Ceram. Soc. 97, 3519 (2014).

${ }^{10}$ B. Singarapu, D. Galusek, A. Durán, and M.J. Pascual, Applied Sciences 10, 2791 (2020).

${ }^{11}$ S. Zhou, J. Hao, and J. Qiu, Journal of the American Ceramic Society 94, 2902 (2011).

${ }^{12}$ S. Yoo, U.-C. Paek, and W.-T. Han, Journal of Non-Crystalline Solids 315, 180 (2003).

${ }^{13}$ S. Wang and K. Liang, Chemosphere 69, 1798 (2007).

${ }^{14}$ Y. Yu, Z. Fang, C. Ma, H. Inoue, G. Yang, S. Zheng, D. Chen, Z. Yang, A. Masuno, J.

Orava, S. Zhou, and J. Qiu, NPG Asia Materials 8, e318 (2016).

${ }^{15}$ O. Dargaud, L. Cormier, N. Menguy, and G. Patriarche, J. Non-Cryst. Solids 358, 1257 (2012).

${ }^{16}$ O. Dargaud, L. Cormier, N. Menguy, G. Patriarche, and G. Calas, Appl. Phys. Lett. 99, 021904 (2011).

${ }^{17}$ V.N. Sigaev, N.V. Golubev, E.S. Ignat'eva, B. Champagnon, D. Vouagner, E. Nardou, R. Lorenzi, and A. Paleari, Nanoscale 5, 299 (2013).

${ }^{18}$ J. Qiu, Int J Appl Glass Sci 7, 270 (2016).

${ }^{19}$ T. Komatsu and T. Honma, Journal of Asian Ceramic Societies 1, 9 (2013).

${ }^{20}$ Z. Fang, S. Zheng, W. Peng, H. Zhang, Z. Ma, G. Dong, S. Zhou, D. Chen, and J. Qiu, Opt. Express 23, 28258 (2015).

${ }^{21}$ K.E. Downey, B.N. Samson, G.H. Beall, E.J. Mozdy, L.R. Pinckney, N.F. Borrelli, A. Mayolet, and A. Kerdoncuff, in (2001), pp. 211-212.

${ }^{22}$ Z. Fang, S. Zheng, W. Peng, H. Zhang, Z. Ma, S. Zhou, D. Chen, and J. Qiu, J. Am. Ceram. Soc. 98, 2772 (2015).

${ }^{23}$ Y.-C. Huang, C.-N. Liu, Y.-S. Lin, J.-S. Wang, W.-L. Wang, F.-Y. Lo, T.-L. Chou, S.-L. Huang, and W.-H. Cheng, Opt. Express 21, 4790 (2013). 
${ }^{24}$ A. Edgar, in Springer Handbook of Electronic and Photonic Materials, edited by S. Kasap and P. Capper (Springer International Publishing, Cham, 2017), pp. 1-1.

${ }^{25}$ B. Wu, S. Zhou, J. Ruan, Y. Qiao, D. Chen, C. Zhu, and J. Qiu, Opt. Express 16, 2508 (2008).

${ }^{26}$ J. Luo, S. Zhou, B. Wu, H. Yang, S. Ye, B. Zhu, and J. Qiu, J. Mater. Res. 24, 310 (2009).

${ }^{27}$ B. Wu, S. Zhou, J. Ruan, Y. Qiao, D. Chen, C. Zhu, and J. Qiu, Appl. Phys. Lett. 92, 151102 (2008).

${ }^{28}$ B. Wu, J. Ruan, J. Ren, D. Chen, C. Zhu, S. Zhou, and J. Qiu, Appl. Phys. Lett. 92, 041110 (2008).

${ }^{29}$ Z. Gao, X. Lu, Y. Zhang, S. Guo, L. Liu, G. Yang, Y. Liu, S. Sun, J. Ren, and J. Yang, Journal of the American Ceramic Society 102, 1619 (2019).

${ }^{30}$ K.E. Lipinska-Kalita, P.E. Kalita, D.M. Krol, R.J. Hemley, C.L. Gobin, and Y. Ohki, Journal of Non-Crystalline Solids 352, 524 (2006).

${ }^{31}$ G. Lakshminarayana and L. Wondraczek, Journal of Solid State Chemistry 184, 1931 (2011).

${ }^{32}$ S. Zhou, N. Jiang, K. Miura, S. Tanabe, M. Shimizu, M. Sakakura, Y. Shimotsuma, M. Nishi, J. Qiu, and K. Hirao, J. Am. Chem. Soc. 132, 17945 (2010).

${ }^{33}$ Y. Yu and X. Li, Materials Research Bulletin 73, 96 (2016).

${ }^{34}$ H. Lin, R. Zhang, D. Chen, Y. Yu, A. Yang, and Y. Wang, J. Mater. Chem. C 1, 1804 (2013).

${ }^{35}$ Z. Gao, S. Guo, X. Lu, J. Orava, T. Wagner, L. Zheng, Y. Liu, S. Sun, F. He, P. Yang, J. Ren, and J. Yang, Advanced Optical Materials 6, 1701407 (2018).

${ }^{36}$ D. Chen, S. Liu, W. Xu, and X. Li, J. Mater. Chem. C 5, 11769 (2017).

${ }^{37}$ Z. Fang, Y. Li, F. Zhang, Z. Ma, G. Dong, and J. Qiu, J. Am. Ceram. Soc. 98, 1105 (2015).

${ }^{38}$ M. Peng, D. Chen, J. Qiu, X. Jiang, and C. Zhu, Opt. Mater. 29, 556 (2007).

${ }^{39}$ C. Jiang, Opt. Express 17, 6759 (2009).

${ }^{40}$ I. Alekseeva, O. Dymshits, M. Tsenter, and A. Zhilin, J. Non-Cryst. Solids 357, 2209 (2011).

${ }^{41}$ P. Li, M. Peng, L. Wondraczek, Y. Zhao, and B. Viana, J. Mater. Chem. C 3, 3406 (2015).

${ }^{42}$ V.M. Orera and R.I. Merino, Boletín de La Sociedad Española de Cerámica y Vidrio 54, 1 (2015).

${ }^{43}$ M.Yu. Sharonov, A.B. Bykov, S. Owen, V. Petricevic, R.R. Alfano, G.H. Beall, and N. Borrelli, J. Opt. Soc. Am. B 21, 2046 (2004).

${ }^{44}$ T. Suzuki and Y. Ohishi, Appl. Phys. Lett. 84, 3804 (2004). 
${ }^{45}$ S. Tanabe and X. Feng, Appl. Phys. Lett. 77, 818 (2000).

${ }^{46}$ T. Suzuki, G.S. Murugan, and Y. Ohishi, Appl. Phys. Lett. 86, 131903 (2005).

${ }^{47}$ S. Zhou, N. Jiang, B. Wu, J. Hao, and J. Qiu, Adv. Funct. Mater. 19, 2081 (2009).

${ }^{48}$ B. Wu, S. Zhou, J. Ren, D. Chen, X. Jiang, C. Zhu, and J. Qiu, Appl. Phys. B 87, 697 (2007).

${ }^{49}$ S. Zhou, G. Feng, B. Wu, N. Jiang, S. Xu, and J. Qiu, J. Phys. Chem. C 111, 7335 (2007).

${ }^{50}$ V.N. Sigaev, N.V. Golubev, E.S. Ignat'eva, V.I. Savinkov, M. Campione, R. Lorenzi, F. Meinardi, and A. Paleari, Nanotechnology 23, 015708 (2012).

${ }^{51}$ B. Wu, S. Zhou, J. Qiu, M. Peng, L. Yang, X. Jiang, and C. Zhu, Chin. Phys. Lett. 23, 2778 (2006).

${ }^{52}$ V.V. Golubkov, T.I. Chuvaeva, O.S. Dymshits, A.A. Shashkin, A.A. Zhilin, W.-B. Byun, and K.-H. Lee, Glass Phys. Chem. 30, 300 (2004).

${ }^{53}$ B. Wu, J. Qiu, M. Peng, J. Ren, X. Jiang, and C. Zhu, Mater. Res. Bull. 42, 762 (2007).

${ }^{54}$ A. Dugué, O. Dymshits, L. Cormier, P. Loiko, I. Alekseeva, M. Tsenter, K. Bogdanov, G. Lelong, and A. Zhilin, Journal of Alloys and Compounds 780, 137 (2019).

${ }^{55}$ G. Gao, S. Reibstein, E. Spiecker, M. Peng, and L. Wondraczek, J. Mater. Chem. 22, 2582 (2012).

${ }^{56}$ B. Wu, J. Qiu, E. Wu, and H. Zeng, Opt. Mater. 35, 983 (2013).

${ }^{57}$ B. Wu, S. Zhou, J. Ren, Y. Qiao, D. Chen, C. Zhu, and J. Qiu, J. Phys. Chem. Solids 69, 891 (2008).

${ }^{58}$ Z. Gao, Y. Liu, J. Ren, Z. Fang, X. Lu, E. Lewis, G. Farrell, J. Yang, and P. Wang, Scientific Reports 7, (2017).

${ }^{59}$ L.R. Pinckney Beal, G.H., J. Non-Cryst. Solids 219, 219 (1997).

${ }^{60}$ V.V. Golubkov, O.S. Dymshits, V.I. Petrov, A.V. Shashkin, M.Ya. Tsenter, A.A. Zhilin, and Uk. Kang, J. Non-Cryst. Solids 351, 711 (2005).

${ }^{61}$ G.H. Beall and D.A. Duke, Journal of Materials Science 4, 340 (1969).

${ }^{62}$ K. Tanaka, T. Mukai, T. Ishihara, K. Hirao, N. Soga, S. Sogo, M. Ashida, and R. Kato, J American Ceramic Society 76, 2839 (1993).

${ }^{63}$ G.H. Beall and L.R. Pinckney, J. Am. Ceram. Soc. 82, 5 (1999).

${ }^{64}$ C. Fernandez-Martin, G. Bruno, A. Crochet, D. Ovono Ovono, M. Comte, and L. Hennet, J. Am. Ceram. Soc. 95, 1304 (2012).

65 J. Zheng and Y. Cheng, Optical Materials 62, 341 (2016).

${ }^{66}$ T. Suzuki, Y. Arai, and Y. Ohishi, J. Luminesc. 128, 603 (2008).

${ }^{67}$ G. Gao, M. Peng, and L. Wondraczek, Opt. Lett. 37, 1166 (2012). 
${ }^{68}$ S. Zhou, G. Feng, B. Wu, S. Xu, and J. Qiu, J. Phys. D: Appl. Phys. 40, 2472 (2007).

${ }^{69}$ P.A. Loiko, O.S. Dymshits, A.A. Zhilin, I.P. Alekseeva, and K.V. Yumashev, J. Non Cryst. Solids 376, 99 (2013).

${ }^{70}$ T. Suzuki, K. Horibuchi, and Y. Ohishi, J. Non-Cryst. Solids 351, 2304 (2005).

${ }^{71}$ S. Zhou, C. Li, G. Yang, G. Bi, B. Xu, Z. Hong, K. Miura, K. Hirao, and J. Qiu, Adv. Funct. Mater. 23, 5436 (2013).

${ }^{72}$ Y. Zhuang, Y. Teng, J. Luo, B. Zhu, Y. Chi, E. Wu, H. Zeng, and J. Qiu, Appl. Phys. Lett. 95, 111913 (2009).

${ }^{73}$ D. Deng, H. Ma, S. Xu, Q. Wang, L. Huang, S. Zhao, H. Wang, and C. Li, J. Opt. Soc. Am. B 27, 1659 (2010).

${ }^{74}$ Q. Yang, H. Ma, D. Deng, and S. Xu, Materials Letters 193, 119 (2017).

${ }^{75}$ V.A. Ivanov, D.V. Simanovskiy, M.O. Marychev, P.V. Andreev, I. Koseva, P. Tzvetkov, and V. Nikolov, Journal of Non-Crystalline Solids 456, 76 (2017).

${ }^{76}$ K.A. Subbotin, V.A. Smirnov, E.V. Zharikov, L.D. Iskhakova, V.G. Senin, V.V. Voronov, and I.A. Shcherbakov, Optical Materials 32, 896 (2010).

${ }^{77}$ J. Kunitomo, R. Suzuki, Y. Takahashi, T. Miyazaki, N. Terakado, and T. Fujiwara, J. Ceram. Soc. Japan 122, 725 (2014).

${ }^{78}$ Z. Pan, Y.-Y. Lu, and F. Liu, Nature Mater 11, 58 (2012).

${ }^{79}$ Y. Li, M. Gecevicius, and J. Qiu, Chem. Soc. Rev. 45, 2090 (2016).

${ }^{80}$ A. Abdukayum, J.-T. Chen, Q. Zhao, and X.-P. Yan, J. Am. Chem. Soc. 135, 14125 (2013).

${ }^{81}$ Y. Zhuang, J. Ueda, and S. Tanabe, Appl. Phys. Lett. 105, 191904 (2014).

${ }^{82}$ M. Allix, S. Chenu, E. Véron, T. Poumeyrol, E.A. Kouadri-Boudjelthia, S. Alahraché, F. Porcher, D. Massiot, and F. Fayon, Chem. Mater. 25, 1600 (2013).

${ }^{83}$ S. Chenu, E. Veron, C. Genevois, A. Garcia, G. Matzen, and M. Allix, J. Mater. Chem. C 2, 10002 (2014).

${ }^{84}$ D. Chen, Journal of the European Ceramic Society 34, 4069 (2014).

${ }^{85}$ Q. Luo, X. Qiao, X. Fan, B. Fan, and X. Zhang, J. Am. Ceram. Soc. 94, 1670 (2011).

${ }^{86}$ S. Lv, B. Shanmugavelu, Y. Wang, Q. Mao, Y. Zhao, Y. Yu, J. Hao, Q. Zhang, J. Qiu, and S. Zhou, Advanced Optical Materials 6, 1800881 (2018).

${ }^{87}$ Z. Zhang, X. Li, C. Wang, and X. Qiao, Phys. Chem. Chem. Phys. 21, 17047 (2019).

${ }^{88}$ D. Chen, Z. Wan, Y. Zhou, and Z. Ji, Journal of the European Ceramic Society 35, 4211 (2015).

${ }^{89}$ Z. Cai, S. Kang, X. Huang, X. Song, X. Xiao, J. Qiu, and G. Dong, J. Mater. Chem. C 6, 9932 (2018). 
${ }^{90}$ D. Chen, Z. Wan, and S. Liu, Anal. Chem. 88, 4099 (2016).

${ }^{91}$ P. Loiko, O.S. Dymshits, V.V. Vitkin, N.A. Skoptsov, A.A. Zhilin, D.V. Shemchuk, M.Ya. Tsenter, K. Bogdanov, A.M. Malyarevich, I.V. Glazunov, X. Mateos, and K.V. Yumashev, Appl. Opt. 55, 5505 (2016).

${ }^{92}$ I. Alekseeva, O. Dymshits, M. Tsenter, A. Zhilin, V. Golubkov, I. Denisov, N. Skoptsov, A. Malyarevich, and K. Yumashev, J. Non-Cryst. Solids 356, 3042 (2010).

${ }^{93}$ A.M. Malyarevich, I.A. Denisov, Y.V. Volk, K.V. Yumashev, O.S. Dymshits, and A.A. Zhilin, J. Alloy. Comp. 341, 247 (2002).

${ }^{94}$ Yu.V. Volk, A.M. Malyarevich, K.V. Yumashev, O.S. Dymshits, A.V. Shashkin, and A.A. Zhilin, J Appl Spectrosc 74, 140 (2007).

${ }^{95}$ S.Y. Feng, C.L. Yu, L. Chen, S.G. Li, W. Chen, and L.L. Hu, Laser Phys. 20, 1687 (2010).

${ }^{96}$ P.A. Loiko, O.S. Dymshits, V.V. Vitkin, N.A. Skoptsov, A.A. Kharitonov, A.A. Zhilin, I.P. Alekseeva, S.S. Zapalova, A.M. Malyarevich, I.V. Glazunov, and K.V. Yumashev, Laser Phys. Lett. 12, 035803 (2015).

${ }^{97}$ L. Lin, Y. Wang, B. Lan, J. Chen, S. Lv, Y. Zhao, H. Yu, J. Hao, Q. Zhang, Z. Yang, H. Zhang, J. Wang, J. Qiu, and S. Zhou, J. Phys. Chem. C 123, 29343 (2019).

${ }^{98}$ J. Chen, Z. Shi, S. Zhou, Z. Fang, S. Lv, H. Yu, J. Hao, H. Zhang, J. Wang, and J. Qiu, Advanced Optical Materials 7, 1801413 (2019).

${ }^{99}$ Y. Yu, F. Huang, D. Chen, H. Lin, R. Zhang, A. Yang, K. Li, and Y. Wang, Laser Phys. 24, 025101 (2014).

${ }^{100}$ S. Wang, Environ. Sci. Technol. 44, 4816 (2010).

${ }^{101}$ S.-M. Wang, F.-H. Kuang, Q.-Z. Yan, C.-C. Ge, and L.-H. Qi, Journal of Alloys and Compounds 509, 2819 (2011).

${ }^{102}$ O.S. Dymshits, A.A. Zhilin, T.I. Chuvaeva, and M.P. Shepilov, J. Non Cryst. Solids 127, 44 (1991). 
FIGURE CAPTION

Figure 1: Schematic diagram of TGCs containing spinel nanocrystals with octahedral and tetrahedral sites available for doping with TM ions (adapted from Zhuang et al. ${ }^{9}$ ). Reprinted with permission from Zhuang et al. NPG Asia Materials 97, 3519 (2014). Copyright (2014), John Wiley and Sons.

Figure 2: (a) HAADF-STEM glass micrograph revealing the presence of mesoscale heterogeneities in a $\mathrm{Li}_{2} \mathrm{O}-\mathrm{Ta}_{2} \mathrm{O}_{5}-\mathrm{Al}_{2} \mathrm{O}_{3}-\mathrm{SiO}_{2}$ glass. (b) Line profile of the contrast line in a. (c) $\mathrm{X}$ ray Diffraction patterns of the glass, the composite GC containing $\mathrm{LiTaO}_{3}$ and $\mathrm{LiAlSi}_{2} \mathrm{O}_{6}$ crystals. (d) Optical cross-section micrograph of the multiphase fiber. (e and f) Raman mapping in the core region of the fiber for the bands at $593 \mathrm{~cm}^{-1}$ and $486 \mathrm{~cm}^{-1}$ corresponding to the fingerprints of $\mathrm{LiTaO}_{3}$ and $\mathrm{LiAlSi}_{2} \mathrm{O}_{6}$ crystals, respectively. (g) Photograph of the activated fiber. ( $h$ and i) Energy Dispersive X-ray mappings of Ta and Al elements in the core region of the activated fiber. Reprinted with permission from Yu et al. NPG Asia Materials 8, e318 (2016), Copyright (2016) Springer Nature. 


\section{Transparent Glass Ceramics}

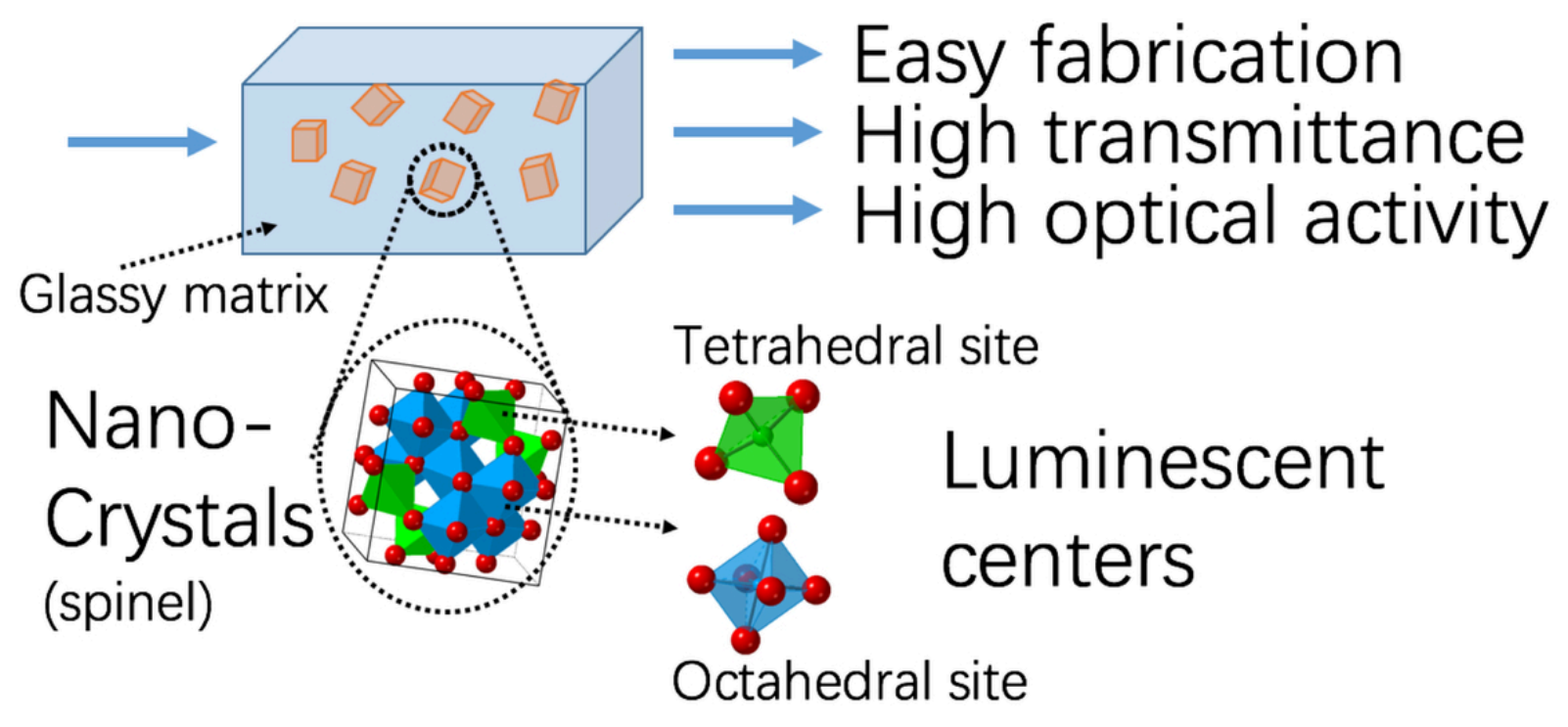




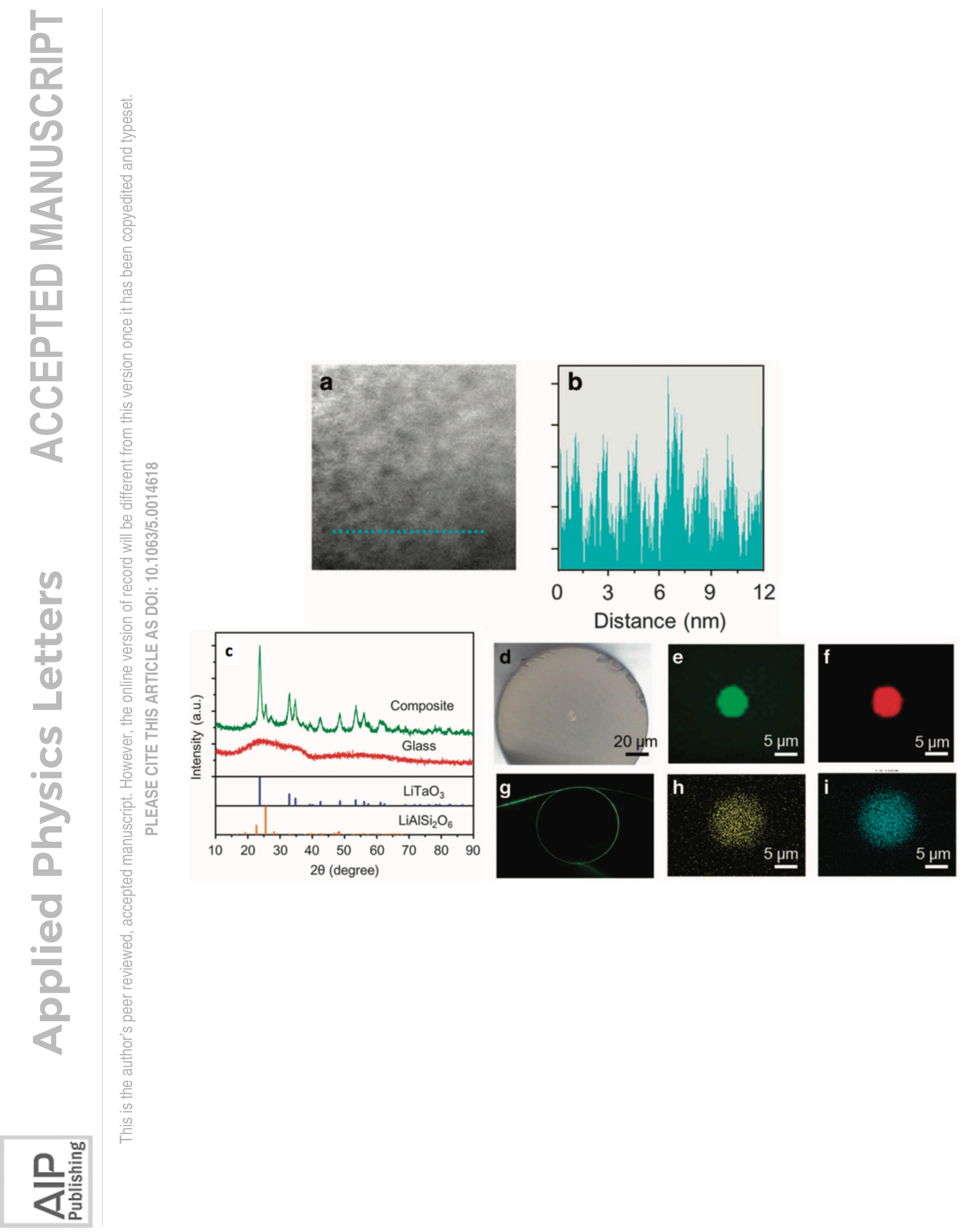

